\title{
Tobacco smoking in Tanzania, East Africa: population based smoking prevalence using expired alveolar carbon monoxide as a validation tool
}

\author{
K Jagoe, R Edwards, F Mugusi, D Whiting, N Unwin
}

Tobacco Control 2002;11:210-214

See end of article for authors' affiliations

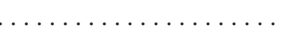

Correspondence to: Kirstie Jagoe, Department of Medicine, University of Newcastle-upon-Tyne Framlington Place, Newcastle-upon-Tyne, NE2 4AA, UK;

kirstiejagoe@hotmail.com

Manuscript received 8 May 2001 and revision

requested 1 August 2001

Accepted 20 March 2002

\begin{abstract}
Objectives: To describe the prevalence of tobacco smoking in an urban East African population while using a simple validation procedure to examine the degree of under reporting in men and women. Design: A cross sectional population based study in adults (15 years and over) with sampling from a well maintained census register.

Setting: llala llala, a middle income district of Dar es Salaam, Tanzania.

Subjects: An age and sex stratified random sample of 973 men and women.

Main outcome measures: Self reported smoking status with correction by exhaled alveolar carbon monoxide (EACO).

Results: From the 605 participants (response rate $67.9 \%$ ) age standardised (new world population) smoking prevalence, based on questionnaire and EACO, was $27.0 \%$ (95\% confidence interval (CI) $20.8 \%$ to $33.2 \%)$ in males and $5.0 \%(95 \% \mathrm{Cl} 2.8 \%$ to $7.2 \%)$ in females. The age specific prevalence of smoking was highest in the age group 35-54 years $(34.3 \%)$ for men and in the over 54 years group $(16 \%)$ for women. Of those classified as smokers, $7.3 \%$ of men and $27.3 \%$ of women were reclassified as current smokers based on EACO ( $\geqslant 9$ parts per million), after they had reported themselves to be an ex- or non-smoker in the questionnaire.

Conclusions: The data suggest: (1) high rates of smoking among men in an urban area of East Africa; and (2) the importance of validating self reports of smoking status, particularly among women.
\end{abstract}

Ir here has been a dramatic increase in smoking in developing countries over the last 25 years. ${ }^{1}$ It is estimated that by 2030 there will be 10 million deaths caused each year by tobacco, and if current smoking prevalence trends continue $70 \%$ of these deaths will be in developing countries. ${ }^{2}$ The economic and public health effects will be substantial in countries that can least afford it.

However, in much of sub-Saharan Africa there are no validated comparable population based data available. In the "Tobacco control country profiles" prepared for the 11 th World Conference on Tobacco or Health in 2000, information about tobacco use in Africa was described as "sparse" with data on smoking prevalence available only from "... scattered surveys in a few countries. Surveys of smoking behaviour, when available, usually only cover urban populations, selected regions, or specific population subgroups such as university students, occupational groups and hospital patients, and are rarely nationally representative." ${ }^{\prime 3}$ Smoking prevalence data were available from countries representing $92.3 \%$ of the world's population while in the World Health Organization's Africa region countries with smoking prevalence data represented only $55.3 \%$ of the population, by far the lowest proportion for any region. ${ }^{4}$

The available data suggest that the WHO Africa region has among the world's lowest smoking prevalence-about $36 \%$ for men and $9 \%$ for women in one estimate ${ }^{4}$ and $29 \%$ for men and $4 \%$ for women in another. ${ }^{5}$ Per capita consumption is also low. In $1995^{6}$ sub-Saharan Africa had the world's lowest number of cigarettes smoked per year by World Bank region-an estimated 700 cigarettes per adult in 1990-92 compared with 1200 per adult average in all developing countries.

Trends in smoking prevalence and consumption in Africa are unclear. Consumption increased in seven selected African countries, ${ }^{7}$ by an estimated $50-174 \%$ between $1970-72$ and 1990-92. Others argue that cigarette consumption is "not growing particularly fast" in the African region, and give examples of declining cigarette sales in South Africa, Zimbabwe, Democratic Republic of Congo, and Ghana between 1990 and $1995 .{ }^{8}$

Most previous studies examining smoking prevalence in East Africa have focused on occupational or other selected groups such as hospital patients. ${ }^{9-11}$ The few published population based studies from Africa show smoking prevalence to be much higher in men than women. ${ }^{12-16}$ However, under reporting of smoking habits may occur, particularly in women from cultures where social and economic constraints still exist. ${ }^{17}$ We are unaware of population based studies from Africa that have validated self reported smoking with biological markers such as exhaled alveolar carbon monoxide (EACO) or urinary cotinine.

The primary objective of this study is to describe the age and sex specific prevalence of tobacco smoking while measuring EACO to test the degree of under reporting in men and women in an urban area of Tanzania. We also investigated cigarette consumption, age of starting to smoke, and reasons for quitting.

\section{SUBJECTS AND METHODS}

\section{Subjects and setting}

The survey was carried out in November 1998 in Ilala Ilala, a ward in a middle income urban area of Dar es Salaam, Tanzania's largest city. Most of the population are employed in semi-skilled jobs and live in closely sited single storey buildings made from mud or brick. Most buildings house up to six family groups who share cooking and washing areas.

An age stratified sample of 973 adults resident in Ilala Ilala (representing $9.9 \%$ of this area's population) was randomly selected from a recent census register of the Adult Morbidity and Mortality Project (AMMP). ${ }^{18}$ The census is undertaken 
Table 1 Age and sex characteristics of the sample after adjustment for migration and death, and study population

\begin{tabular}{llll}
\hline & Males & Females & Total \\
\hline Sample (n) & 468 & 423 & 891 \\
Response & $286(61.2 \%)$ & $319(75.4 \%)$ & $605(67.9 \%)$ \\
Response by age groups & $102(64.2 \%)$ & $110(71.4 \%)$ & \\
$15-34$ years & $99(55.6 \%)$ & $103(76.9 \%)$ & \\
$35-54$ years & $85(64.9 \%)$ & $106(78.5 \%)$ & \\
$55+$ years & $42.7(18.1)$ & $43.9(18.1)$ & $42.9(17.5)$ \\
Study participants & $15-94$ & $15-98$ & $15-98$ \\
$\quad$ Mean (SD) age (years) & & & \\
\hline Age range & & & \\
\hline
\end{tabular}

every six months as part of an ongoing demographic surveillance system. Based on data from AMMP and our experience in a previous survey, ${ }^{19}$ we estimated that this sample would give us 600 (300 men and 300 women) subjects after allowing for anticipated non-response caused by migration, refusal or death. We anticipated the main reason for non-response would be failure to contact potential subjects as a result of migration within Dar es Salaam or to other areas of Tanzania. Within the constraints of the resources available, the sample size was chosen to provide reasonably precise overall estimates of smoking prevalence by sex. For example, assuming a $20 \%$ prevalence in a group of 300 the $95 \%$ confidence intervals (CI) would be $15.5 \%$ to $24.5 \%$, and with a prevalence of $5 \%, 95 \%$ CI $2.5 \%$ to $7.5 \%$. We stratified the sample by the following age groups: 15-34, 35-54, 55 years or older. We aimed to recruit 100 per age and sex group.

\section{Methods and materials}

We employed a pre-piloted structured questionnaire to collect information on smoking patterns, domestic environment, and respiratory symptoms. Questions were based on three validated questionnaires. The section that examined smoking habits was taken from the Tasmanian Smoking Survey. ${ }^{20}$ The questionnaire was translated into Kiswahili with back translation to English and revision where necessary to ensure direct translation was achieved. Appropriately trained local field workers carried out an interview based on the questionnaire in the subjects' home.
We made strenuous efforts to include all individuals. Subjects were classified as non-responders if they were not present when visited at their home on three separate occasions at different times of the day on different days during the week. If a subject was too frail or sick to participate, their next of kin gave responses in their presence.

We measured EACO using a Bedfont Smokerlyzer EC50 (Bedfont Scientific, Upchurch, UK) as per manufacturers instructions. This was calibrated four times per week using standard calibration gas ( 50 parts per million (ppm)).

Current smokers were defined as subjects who gave a positive reply to both of the questions "Have you ever smoked regularly?" and "Do you currently smoke?". "Regularly" and "current" were defined as "at least one cigarette a day". We also classified subjects as a current smoker if they had a positive EACO measurement ( $\geqslant 9 \mathrm{ppm})$ regardless of their self reported smoking status. Ex-smokers were defined as those who replied positively to the question "Have you ever smoked regularly?", negatively to the question "Do you currently smoke?", and had an EACO of $<9$ ppm. Non-smokers replied negatively to both the questions "Have you ever smoked regularly?" and "Do you currently smoke?", and had a negative EACO measurement. Participants who refused to perform the EACO test were classified by their self reported smoking status only.

In order to investigate potential confounding from exposure to cooking fuels on EACO levels, we asked women about their exposure to cooking fuel in the house. Those using charcoal,

Table 2 Crude and age standardised prevalence rates of current and ex-smoking by age and sex

\begin{tabular}{|c|c|c|c|c|c|c|}
\hline & \multicolumn{2}{|c|}{ Current smoker* } & \multicolumn{2}{|c|}{ Ex-smokert } & \multicolumn{2}{|c|}{ Non-smokerł } \\
\hline & $\mathrm{n}$ & $\%(95 \% \mathrm{Cl})$ & $\mathrm{n}$ & $\%(95 \% \mathrm{Cl})$ & $\mathrm{n}$ & $\%(95 \% \mathrm{Cl})$ \\
\hline \multicolumn{7}{|l|}{ Female } \\
\hline $15-34$ years & 2 & $1.8(0.2$ to 6.4$)$ & 0 & $0.0(0.0$ to 3.3$)$ & 108 & 98.1 (93.6 to 99.8 ) \\
\hline $35-54$ years & 3 & $2.9(0.6$ to 8.3$)$ & 5 & $4.9(1.6$ to 11.0$)$ & 95 & $92.2(85.3$ to 96.6$)$ \\
\hline $55+$ years & 17 & $16.0(9.1$ to 23.0$)$ & 24 & 22.6 (14.7 to 30.6$)$ & 65 & $61.3(52.0$ to 70.6$)$ \\
\hline Total & 22 & 6.9 (4.4 to 10.3 ) & 29 & 9.1 (6.2 to 12.8 ) & 268 & $84.0(80.0$ to 88.0$)$ \\
\hline Age adjusted§ & & $5.0(2.8$ to 7.2$)$ & & $6.2(3.9$ to 8.5$)$ & & \\
\hline Age adjusted & & $3.0(1.0$ to 5.0$)$ & & 2.7 (1.6 to 3.8 ) & & \\
\hline \multicolumn{7}{|l|}{ Male } \\
\hline $15-34$ years & 22 & 21.6 (13.6 to 29.6 ) & 8 & 7.8 (3.5 to 14.9$)$ & 72 & 70.6 (61.7 to 79.4$)$ \\
\hline $35-54$ years & 34 & $34.3(25.1$ to 44.6$)$ & 24 & 24.2 (16.2 to 33.9$)$ & 41 & 41.4 (31.6 to 51.8$)$ \\
\hline $55+$ years & 26 & $30.6(21.1$ to 41.5$)$ & 23 & 27.1 (18.0 to 37.8 ) & 36 & $42.4(31.7$ to 53.6$)$ \\
\hline Total & 82 & 28.7 (23.4 to 33.9 ) & 55 & 19.2 (14.7 to 23.8 ) & 149 & 52.1 (46.3 to 57.9 ) \\
\hline Age adjusted§ & & 27.0 (20.8 to 33.2$)$ & & 16.1 (11.6 to 20.6$)$ & & \\
\hline Age adjusted & & $26.2(19.6$ to 32.8$)$ & & $14.4(9.9$ to 18.9$)$ & & \\
\hline \multicolumn{7}{|c|}{$\begin{array}{l}\text { \%, of sex/age group. } \\
\text { *Subjects who currently smoke more than one cigarette daily and had an EACO reading of }>9 \mathrm{ppm} \text {. } \\
\text { † Subjects who have smoked more than one cigarette daily but no longer does and had an EACO reading of }<9 \mathrm{ppm} \text {. } \\
\text { †Subjects who deny ever smoking more than one cigarette daily and had an EACO reading of }<9 \mathrm{ppm} \text {. } \\
\text { §Directly age standardised prevalence (new world population). } \\
\text { ๆDirectly age standardised prevalence (llala llala population structure). }\end{array}$} \\
\hline
\end{tabular}


Table 3 Characteristics of smoking habits

\begin{tabular}{|c|c|c|}
\hline & Male & Female \\
\hline \multicolumn{3}{|l|}{$\begin{array}{l}\text { Smoking classification (\% of } \\
\text { current smokers/sex group (n)) }\end{array}$} \\
\hline Quest +ve \& CO +ve & $63.4(52)$ & $40.9(9)$ \\
\hline Quest +ve \& CO -ve & $29.3(24)$ & $31.8(7)$ \\
\hline Quest-ve \& CO +ve & $7.3(6)$ & $27.3(6)$ \\
\hline \multicolumn{3}{|l|}{ Mean (SD) age started smoking } \\
\hline $15-34$ years & $18.6(5.10)$ & $22.5(0.71)$ \\
\hline $35-54$ years & $22.8(6.15)$ & $21.5(4.46)$ \\
\hline $55+$ years & $22.8(7.85)$ & $22.7(5.34)$ \\
\hline Total & $21.9(6.8)$ & $22.6(5.09)$ \\
\hline $\begin{array}{l}\text { Median (range) }{ }^{*} \text { number } \\
\text { smoked per day (current } \\
\text { smokers) }\end{array}$ & $n=74$ & $\mathrm{n}=15$ \\
\hline $15-34$ years & $6(1-20)$ & $1(-)$ \\
\hline $35-54$ years & $8(2-30)$ & $5(-)$ \\
\hline $55+y r s$ & $5(2-40)$ & $3(1-20)$ \\
\hline Total & $6(1-40)$ & $3(1-20)$ \\
\hline $\begin{array}{l}\text { Median (range) }{ }^{*} \text { years smoked } \\
\text { (current smokers) }\end{array}$ & $n=79$ & $n=19$ \\
\hline $15-34$ years & $4(1-17)$ & $1.5(1-2)$ \\
\hline $35-54$ years & $19(2-39)$ & $20(-)$ \\
\hline $55+$ years & $40(11-63)$ & $39.5(29-65)$ \\
\hline Total & $20(1-63)$ & $39(1-65)$ \\
\hline \multicolumn{3}{|l|}{ Pack years* } \\
\hline Ex-smokers median (range) & $n=53$ & $\mathrm{n}=31$ \\
\hline $15-34$ years & $0.15(0.004-9)$ & $0(-)$ \\
\hline $35-54$ years & $0.83(0.1-28)$ & $0.9(0.001-5)$ \\
\hline $55+$ years & $12.4(0.6-90)$ & $1.68(0.1-40)$ \\
\hline Total & $5.0(.004-90)$ & $1.6(0.001-40)$ \\
\hline Median (range) current smokers & $\mathrm{n}=71$ & $\mathrm{n}=15$ \\
\hline $15-34$ years & $1(0.1-6)$ & $<1(-)$ \\
\hline $35-54$ years & $7(0.3-39)$ & $5(-)$ \\
\hline $55+$ years & $9.6(1.1-126)$ & $5(2.8-45)$ \\
\hline Total & $6.48(0.00-126)$ & $5.0(0-45)$ \\
\hline $\begin{array}{l}\text { Reasons for quitting (\% of } \\
\text { ex-smoker/sex group (n)) }\end{array}$ & $\mathrm{n}=55$ & $n=29$ \\
\hline Current health problems & $21.8(12)$ & $34.5(10)$ \\
\hline Potential health problems & $40.0(22)$ & $38.0(11)$ \\
\hline Financial reasons & $5.5(3)$ & $6.9(2)$ \\
\hline Family pressure & $7.3(4)$ & $10.3(3)$ \\
\hline Other & $25.5(14)$ & $10.3(3)$ \\
\hline
\end{tabular}

gas, kerosene or wood more than five times in one week were assigned to a "high exposure" group. Pilot studies and information from local colleagues indicated that very few men were involved with the process of cooking.

\section{Analysis}

Data analysis was performed using the Statistical Package for the Social Sciences (SPSS version 7.5.1) Confidence intervals were calculated using the CIA package (Version 2.0.0). $\chi^{2}$ tests and analysis of variance were used as appropriate. Directly aged standardised rates were calculated using the age structure of Ilala Ilala from the census file and the new world population. $^{21}$

\section{RESULTS}

Six hundred and five subjects, from the 973 sampled, agreed to enter the study. After adjusting for subjects known to have migrated or died ( $8.4 \%$ of sample) since the last census, the response rate was $67.9 \%$. Response was lower for males than for females ( $\mathrm{M} v \mathrm{~F}$ : $61.2 \% v 75.4 \%$, 95\% CI for difference $8.3 \%$ to $20.3 \%$ ) The age and sex characteristics of the population studied are shown in table 1. EACO was measured on $94.9 \%$ of the participating subjects. The remaining 5.1\% ( $\mathrm{M} v \mathrm{~F}: 4.2 \% v$
Table 4 Mean (SD) expired alveolar carbon monoxide in women by cooking exposure level and smoking status

\begin{tabular}{lll}
\hline \multirow{2}{*}{ Smoking status } & \multicolumn{2}{l}{ Cooking exposure level } \\
\cline { 2 - 3 } & Low* & High† \\
\hline Not a current smoker $\ddagger$ & $2.73(1.67)$ & $2.28(2.22)$ \\
Current smoker§ & $9.17(4.71)$ & $11.10(10.9)$ \\
\hline
\end{tabular}

*Exposure to wood, charcoal, kerosene or gas while cooking less than 5 times per week. †Exposure to wood, charcoal, kerosene or gas while cooking more that 5 times per week. $\ddagger$ Any women who denied currently smoking on questionnaire. §Any women who admitted to be currently smoking on questionnaire.

$6.0 \%$ ) either refused or were unable to master the technique required for a satisfactory reading.

The smoking behaviour of males and females subdivided by age group is shown in table 2 . Crude smoking prevalence was $28.7 \%$ (95\% CI $23.4 \%$ to $33.9 \%$ ) in men and $6.9 \%$ (95\% CI $4.4 \%$ to $10.3 \%$ ) in women. The age adjusted rate (directly standardised to the new world population) was $27.0 \%$ (95\% CI $20.8 \%$ to $33.2 \%$ ) in males and $5.0 \%$ (95\% CI $2.8 \%$ to $7.2 \%$ ) in females, and was $26.2 \%$ (95\%CI $19.6 \%$ to $32.8 \%$ ) in men and $3 \%(95 \%$ CI $1.0 \%$ to $5.0 \%$ ) in women when standardised to the Ilala population structure. The age specific prevalence of smoking in men was highest in the age group 35-54 years but highest in women in the over 54 years group. Very few women under the age of 35 years smoked.

If self reported non-smokers, who refused or could not perform the EACO test, were assumed to have a smoking prevalence equal to or twice that of all men or women included in the survey who completed EACO tests, crude prevalence of smoking changed to $29.7 \%$ and $31.1 \%$ in men and $7.2 \%$ and $8.2 \%$ in women.

Most current smokers were identified from their responses in the questionnaire, yet table 3 shows that $7.3 \%$ (95\% CI $2.7 \%$ to $15.3 \%$ ) of male smokers and $27.3 \%$ (95\% CI $10.7 \%$ to $50.2 \%$ ) of female smokers were classified as current smokers based on EACO levels alone. The proportion of women defined as current smokers in this way was significantly greater than for men $\left(\chi^{2}\right.$ test, $\left.\mathrm{p}=0.009\right)$.

Additional details about smoking habits are shown in table 3. The mean age of starting smoking was between $21-23$ years, and similar for men and women (95\% CI for mean difference 1.4 to 2.8 years), although the age range for men starting smoking was broader than for women. Most smokers had low lifetime cigarette consumption, mainly because of a low numbers of cigarettes smoked per day. The median pack years smoked among current smokers was not significantly different between males (6.48 pack years) and females (5.0 pack years), median difference 0.3 (95\% CI for difference -2.9 to 3.2). Male ex-smokers did have higher values for pack years smoking ( $5.0 \vee 1.7$ for females, median difference 1.75 pack years, $95 \%$ CI for difference 0 to 7.9 ). Current or potential health problems was the most common reason given for stopping smoking (65.5\% of ex-smokers). Other reasons given for stopping smoking included religious beliefs and lack of perceived benefit from smoking.

We investigated whether women with heavy exposure to smoke from cooking fuels had been misclassified as smokers. For this analysis non-smokers were categorised as all subjects who denied currently smoking and therefore included ex-smokers. "Smokers" were those people who admitted currently smoking on questionnaire. Table 4 shows mean EACO in high and low cooking smoke exposure groups. Women with high domestic smoke exposure were no more likely to have a raised exhaled carbon monoxide than those with low exposure ( $\chi^{2}$ test, $p=0.65$ ). An analysis of variance (ANOVA) test was used to determine if there was a significant relation 
between cooking exposure and EACO level independent of smoking status. The two were shown to be independent. As expected, smoking exercised a dominant effect on the level of EACO $(p \leqslant 0.0001)$ whereas the level of cooking exposure was not significantly related to EACO levels $(p=0.07)$. There was therefore no evidence to support the suggestion that the "female current smokers", who denied smoking yet had positive CO measurements, were being misclassified because of exposure to $\mathrm{CO}$ from domestic exposures such as cooking.

\section{DISCUSSION}

This study found that smoking is more common in Tanzanian men than women in a middle income area of Dar es Salaam. The prevalence of tobacco smoking is $27 \%$ in males and $5 \%$ in females after direct standardisation to the new world population. These findings are similar to the WHO estimated smoking prevalence in Africa ${ }^{6}$ and other areas of Africa where population based studies have been carried out. ${ }^{14}$

We believe the results provide a good estimate of smoking prevalence in this population. The strengths of this study include the use of a well maintained census register as the basis for a random stratified sample and the use of validated and standardised questions to assess smoking behaviour. This allows for comparison with results from other populations. We also validated self reported smoking with a biochemical marker. To our knowledge this is the first population based study to use EACO to validate self reported smoking in sub-Saharan Africa.

The study has some limitations. The survey occurred over a period of one month. The young men in particular in this community often work away from home or for very long hours. This was reflected in the low response rate $(55.6 \%)$ in males within the $35-54$ years age group and may reduce the validity of the finding in this group. Future studies should take place over longer period of time to allow for seasonal working and travel trends. However, the high female response rate combined with the validation of self reported smoking using EACO should ensure we obtained a robust estimate of female smoking prevalence for this population. Another weakness was that in subgroup analyses the sample sizes were relatively small and the confidence intervals therefore are often wide. The point estimates need to be interpreted in this light. Finally, we only investigated tobacco use through cigarettes. Although we are not aware of the use of other forms of tobacco in this population, tobacco chewing is common in other African countries.'

A previous study in Tanzania from 1987-89, which used data collected using a combination of self reported and proxy reported smoking by heads of households, showed a lower prevalence of tobacco smoking in men in Dar es Salaam $(20.9 \%)$ but similar in women $(3.8 \%) .{ }^{18}$ Other studies found similar rates of smoking in women (2-4\%) in three rural areas of Tanzania, but a much more variable prevalence in men (43\% in Kilamanjaro, 28\% in Morogoro, and 8.6\% in Mara). ${ }^{12}$ This suggests that smoking prevalence is increasing among men in Dar es Salaam, but not among women. The finding of very low lifetime consumption of tobacco in pack years may reflect the economic status of the people in this area of Tanzania.

The results of this study have implications for future surveys of tobacco use in similar populations. We illustrated how questionnaire data can underestimate smoking prevalence when used as the only assessment tool, particularly among women. When prevalence is low, as in this female population, the absolute impact of denial of smoking may be modest. However, as prevalence increases, the underestimate of "true" smoking prevalence could be substantial. Under reporting of smoking will vary with local attitudes and beliefs. Hence, valid international and intercultural comparisons of smoking prevalence, particularly among women, require self reported results to be validated by biochemical methods.

\section{What this paper adds}

There has been a dramatic increase in smoking in developing countries over the last 25 years. However, in much of sub-Saharan Africa there are no validated comparable population based data available and we are not aware of any population based surveys incorporating biochemical validation of smoking status from any African region. Under reporting of smoking habits may occur, particularly in women from cultures where social and economic constraints still exist. We aim to describe the prevalence of tobacco smoking in an urban area of Tanzania and explore the use of exhaled alveolar carbon monoxide for biochemical validation.

This study confirms that smoking is much more common in men than women in this population. Without biochemical validation of self reported smoking, smoking prevalence may be underestimated, particularly among women. Exhaled alveolar carbon monoxide is a practical and effective method for biochemical validation of smoking prevalence surveys in developing countries.

Urinary, salivary or serum cotinine are often viewed as the "gold standard" for detecting and measuring cigarette consumption. In comparison, EACO has a shorter half life of 2-5 hours and may be affected by other environmental sources of carbon monoxide such as passive smoking or road traffic. ${ }^{22}{ }^{23}$ Hence, it is less sensitive and specific, particularly in detecting light smokers or smokers who have not had a cigarette for several hours. Most authors, however, have concluded that EACO is a useful test. Evaluations of EACO in a variety of settings and contexts ${ }^{24-31}$ have mostly assessed sensitivity and specificity in relation to self reported smoking status. Comparisons with serum or salivary thiocyanate have generally found higher specificity and sensitivity for EACO, ${ }^{25}{ }^{27} 32$ while comparisons with serum cotinine have shown EACO performs as well ${ }^{27}{ }^{29}$ or nearly as well. ${ }^{28}$ Furthermore, EACO has some clear advantages as a survey marker, particularly in countries which are poor in resources. It is inexpensive, simple, portable, and non-invasive and therefore likely to be a generally acceptable method across different cultures. It also gives instant results and does not require the kind of laboratory assistance that is extremely difficult to arrange in many developing countries. ${ }^{27} 3334$

The sensitivity and specificity of EACO varies with the population, setting, and cut off point chosen. Studies investigating the best cut off point have suggested concentrations of $6 \mathrm{ppm},{ }^{27} 8 \mathrm{ppm},{ }^{28}$ and $9 \mathrm{ppm}^{32}$ to minimise false negatives and false positives. We chose a cut off point of $9 \mathrm{ppm}$ to achieve a reasonable sensitivity while maximising specificity. We are confident that self reported non-smokers with raised EACO were smokers, though we acknowledge that because of the high cut off point some deceivers (particularly light and irregular smokers) will have been missed. The lack of sensitivity of EACO at this cut off point in a population with a high proportion of light smokers is demonstrated by the finding that about $30 \%$ of self reported smokers had an EACO of $<9 \mathrm{ppm}$. However, we believe that using the combination of self reported smoking status and changing the status only for questionnaire negative, EACO positive subjects is a reasonable approach to measuring smoking prevalence in surveys like this.

The low prevalence of smoking in women found in this study should not encourage complacency. There is substantial evidence of aggressive tobacco marketing in Tanzania. The tobacco companies are increasing their targeting of women in developing countries ${ }^{35}$ at a time when many cultural prohibitions on women are easing with the effects of globalisation, making these women a high risk population for increases in smoking prevalence. ${ }^{3637}$ 
The main reasons for quitting smoking given by ex-smokers were health related. Other studies in Africa have shown similar results to ours. ${ }^{38}{ }^{39}$ This contradicts the view that in many developing counties knowledge of the health effects of tobacco is poor. ${ }^{10}$ However, the information obtained by our survey about knowledge and attitudes to smoking was fairly superficial, and more in-depth research is needed to explore understanding of the level and extent of the health risks associated with smoking, and the impact of that knowledge on behaviour.

The WHO's Tobacco Free Initiative ${ }^{41}$ and the World Bank ${ }^{42}$ have urged countries to develop comprehensive tobacco control strategies. A key requirement for the development and monitoring of such strategies is valid population based smoking prevalence data. Without this, tobacco control is unlikely to be effective. We have shown that without biochemical validation of self reported smoking, smoking prevalence may be underestimated, particularly among women. Validation with a biochemical marker is imperative in order to achieve true smoking prevalence. Based on our experience we believe EACO is a cheap, simple but effective tool to validate self reported smoking information in prevalence surveys in sub-Saharan Africa.

\section{ACKNOWLEDGEMENTS}

This study involved help from staff from a project funded by the Department for International Development of the British government. Specific funding for the study was provided by: Allen \& Hanbury (UK); The Black Swan Public House, Alnwick, Northumberland; Rotary Club, Alnwick Northumberland. We especially thank Dr Seif Rashid for the energy and direction he gave to the field work, the authorities of Ilala Health District, Dar es Salaam, for allowing us to undertake the study, the nurses and medical assistants who assisted with data collection, and the participants who gave time freely. Tanya Pless-Mulloi assisted with the planning of the fieldwork and Philip Setel provided support during sampling and comments towards the final paper.

\section{Authors' affiliations}

K Jagoe, R Edwards, N Unwin, Departments of Medicine and Epidemiology/ Public Health, University of Newcastle-upon-Tyne, Framlington Place, Newcastle-upon-Tyne, UK

F Mugusi, *D Whiting , Muhimbili University College of Health Sciences, Dar es Salaam, Tanzania

*Also Adult Morbidity and Mortality Project (AMMP), Dar es Salaam

\section{REFERENCES}

1 United Nations. Ad hoc inter-agency task force on tobacco control, report of the Secretary- General. New York: United Nations, 2000.

2 World Bank. World Development Report 1993. Investing in health. New York: Oxford University Press for the World Bank, 1993.

3 Corrao MA, Guindon GE, Sharma N, et al. Tobacco control country profiles. Atlanta. Georgia: American Cancer Society, 2000.

4 Corrao MA, Guindon GE, Cokkinides V, et al. Building the evidence base for global tobacco control. Bull WHO 2000;78:884-90.

5 Jha P, Chaloupka F. Tobacco control in developing countries. New York Oxford University Press on behalf of The Human Development Network, the World Bank, and the Economics Advisory Service, World Health Organization, 1999.

6 Mustafa KY, Lakha AS, Milla MH, et al. Byssinosis, respiratory symptoms and spirometric lung function tests in Tanzania workers. $\mathrm{Br} J$ Ind Med 1978;35:123-8.

7 Saloojee Y. Regional summary for the African Region. In: Corrao MA, Guindon GE, Sharma N, et al. Tobacco control country profiles. Atlanta, Georgia: American Cancer Society, 2000.

8 Gajalakshmi CK, Jha P, Ranson K, et al. Global patterns of smoking and smoking-attributable mortality. In: Jha P, Chaloupka F, eds. Tobacco control in developing countries. New York: Oxford University Press on behalf of The Human Development Network, the World Bank, and the Economics Advisory Service, World Health Organization, 1999.
9 Arya OP, Bennett FJ. Smoking among university students in Uganda - an analysis of prevalence and attitudes. East African Med J 1970;47:18-28.

10 Lore W, Lwenya R. Smoking habits in Kenya. II A follow up study involving personnel working at Kenyatta National Hospital, Nairobi. East African Med J 1988;65:71-80.

11 Maher D, Mvula B. A survey of smoking in medical inpatients and controls in Blantyre, Malawi. Tropical Doctor 1996;26:139.

12 Swai ABM, McLarty DG, Kitange HM, et al. Low prevalence of risk factors for coronary heart disease in rural Tanzania. Int J Epidemiol 1993;22;651-9.

13 Berrios X, Koponen T, Huiguang T, et al. Distribution and prevalence of major risk factors of noncommunicable diseases in selected countries: the WHO Inter-Health Programme. Bull WHO 1997;75:99-108.

14 Idris AM, Ibrahim YE, Warnakulasuriya KA, et al. Toombak use and cigarette smoking in the Sudan: estimates of prevalence in the Nile state. Prev Med 1998:27:597-603.

15 Steyn K, Bourne LT, Jooste PL, et al. Smoking in the black community of the Cape Peninsula, South Africa. East African Med J 1994:71:784-9.

16 Moellenze WF, Moore AJ, Steyn AF, et al. Coronary heart disease risk factors in a rural and urban Orange Free State black population. South African Med J 1995;85:90-6.

17 Kaplan M, Carriker L, Waldron I. Gender difference in tobacco use in Kenya. Soc Sci Med 1990;30:305-10.

18 Adult Morbidity and Mortality Project (AMMP). Policy implications of adult morbidity and mortality. End of phase one report. Dar es Salaam: DFID (UK)/United Republic of Tanzania, 1997

19 Edwards R, Unwin N, Mugusi F, et al. Hypertension prevalence and care in an urban and rural community in Tanzania. J Hypertens 2000;18:145-52.

20 Ponsonby AL, Couper D, Dwyer T. Features of infant exposure to tobacco smoke in a cohort study in Tasmania. J Epidemiol Community Health 1996;50:40-6.

21 World Health Organization. 1992 world health statistics annual. Geneva: WHO, 1993

22 Marsh GM, Sachs DPL, Callahan C, et al. Direct methods of obtaining information on cigarette smoking in occupational studies. Am J Ind Med information on ciga

23 Frederiksen LW, Martin JE. Carbon monoxide and smoking behaviour. Addict Behav 1979:4:21-30.

24 Bauman K, Koch G. Validity of self-reports and descriptive and analytical conclusions: the case of cigarette smoking by adolescents and their mothers. Am J Epidemiol 1983;1 18:90-8.

25 Vogt TM, Selvin S, Widdowson G, et al. Expired air carbon monoxide and serum thiocyanate as objective measures of cigarette exposure. Am J Public Health 1977;67:545-9.

26 Petitti DB, Friedman GD, Kahn W. Accuracy of information on smoking habits provided on self-administered research questionnaires. Am J Public Health 1981;71:308-11.

27 Woodward $M$, Tunstall-Pedoe $H$. An iterative technique for identifying smoking deceivers with application to the Scottish heart health study. Prev Med 1992;21:88-97.

28 Jarvis MJ, Tunstall-Pedoe $\mathrm{H}$, Feyerabend $\mathrm{C}$, et al. Comparison of tests used to distinguish smokers from non-smokers. Am J Public Health 1987;77:1435-8.

29 Waage $\mathbf{H}$, Silsand T, Urdal P, et al. Discrimination of smoking status by thiocyanate and cotinine in serum, and carbon monoxide in expired air. Int J Epidemiol 1992;21:488-93.

30 Coletti G, Supnick JA, Abueg FR. Assessment of the relationship between self-reported smoking rate and ecolyzer measurement. Addict Behav 1982; 7:183-8.

31 Hughes JR, Frederiksen LW, Frazier M. A carbon monoxide analyser for measurement of smoking behaviour. Behaviour Therapy 1978;9:293-6.

32 Fortmann SP, Rogers T, Vranizan K, et al. Indirect measures of cigarette use: expired-air carbon monoxide versus plasma thiocyanate. Prev Med 1984:13:127-35.

33 Jarvis MJ, Belcher $M$, Vesey $C$, et al. Low cost carbon monoxide monitors in smoking assessment. Thorax 1986;41:886-7

34 Irving JM, Phil M, Clark EC, et al. Evaluation of a portable measure of expired air carbon monoxide. Prev Med 1988;17:109-115.

35 Jacobson J, Amos A, Aghi M. Women and smoking. Lancet $1989 ; \mathrm{i}: 1193-4$

36 Amos A. Women and smoking. Br Med Bull 1996;52:74-89.

37 World Health Organization. Tobacco or health: a global status report Geneva: WHO, 1997.

38 Leonard L. Cigarette smoking and perceptions about smoking and health in Chad. East African Med J 1996:73:509-13.

39 Steyn K, Bourne LT, Jooste PL, et al. Smoking in the black community of the Cape Peninsula, South Africa. East African Med J 1994;71:784-9.

40 Asma S, Pederson L. Tobacco control in Africa: opportunities for prevention. Tobacco Control 1999:8:353-4.

41 World Health Organization. Confronting the epidemic: a global agenda for tobacco control research. Geneva: WHO Tobacco Free Initiative, 1999

42 World Bank. Curbing the epidemic: governments and the economics of tobacco control. Washington DC: The World Bank, 1999. 